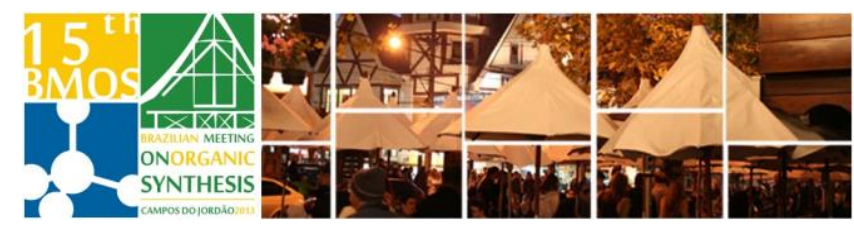

\title{
Multicomponent synthesis of $\boldsymbol{R}$-(+)-limonene-based 1,3,4-thiadiazoles
}

\section{Hugo Falzirolli, Fábio Vandresen, Francieli Furlan, Cleuza Conceição da Silva*.}

FITOSIN - Laboratório de Fitoquímica e Síntese Orgância. Departamento de Química, Universidade Estadual de Maringá. Av. Colombo, 5790, CEP 87020-900, Maringá-PR, Brasil.

\section{*ccsilva@uem.br}

Keywords: Oxidative cyclization, 1,3,4-thiadiazole, $R$-(+)-limonene

\section{INTRODUCTION}

1,3,4-thiadiazoles find application in several areas of modern chemistry and, for this reason, improvements on their synthesis are constantly sought. ${ }^{1} \quad$ The oxidative cyclization involving thiosemicarbazones in the presence of oxidizing agent such as ferric ions lies among the common strategies for the synthesis of this five-membered ring. ${ }^{2}$ Improvements on this method have led to successful one-pot ${ }^{3}$ and solid-phase ${ }^{1}$ syntheses of 1,3,4-thiadiazoles. Looking for biological active molecules, our research group works on semisynthesis of compounds bearing terpenic moiety. Attempting not only to obtain new terpenic 1,3,4thiadiazoles but also optimize their synthesis, an efficient multicomponent method is reported herein, where the cyclization takes place directly from the thiosemicarbazide of $R$-(+)-limonene, aldehyde and the iron(III) chloride.

\section{RESULTS AND DISCUSSION}

The series of 1,3,4-thiadiazoles were obtained by optimization of literature protocols. $^{2,3}$ In this multicomponent approach, 2.2 equivalents of iron(III) chloride hexahydrate were added to a solution of equimolar quantities of thiosemicarbazide of $R-(+)$ limonene 1 (prepared according to literature reports ${ }^{4,5}$ ) and heteroaromatic aldehyde or 4substituted benzaldehyde derivatives as presented in Figure 1.

Figure 1. Multicomponent synthesis of 1,3,4-thiadiazoles.

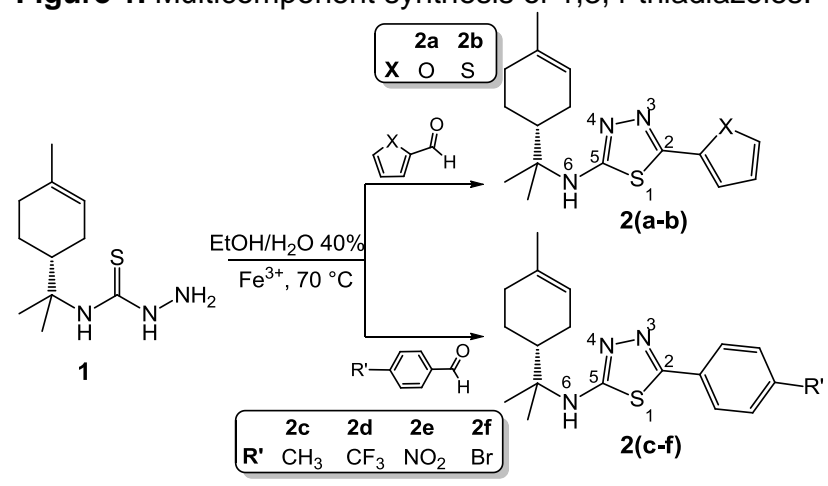

After 2 hours stirring under the specified conditions, the mixture was cooled, filtered and washed with water, affording the 1,3,4-thiadiazoles (2a-f) in fairly good yields, as shown in Table 1.

Table 1. 1,3,4-thiadiazoles yields by multicomponent procedure.

\begin{tabular}{|c|c|c|c|c|c|c|}
\hline Compound & 2a & 2b & 2c & 2d & 2e & 2f \\
\hline Yield (\%) & 69.7 & 71.0 & 76.4 & 81.7 & 80.9 & 86.2 \\
\hline
\end{tabular}

The synthesis of 1,3,4-thiadiazoles was confirmed by their NMR data. The ${ }^{1} \mathrm{H}$ NMR spectra of compounds 2(a-f) evidenced a characteristic singlet between $\delta_{H} 5,45-5,92$ due to the hydrogen linked to nitrogen 6 . The ${ }^{13} \mathrm{C}$ NMR spectra presented signals ranging from $\delta_{\mathrm{C}} 166,0$ to $\delta_{\mathrm{C}} 167,0$ for $\mathrm{C} 2$ and from $\delta_{\mathrm{C}}$ 149,0 to $\delta_{C} 158,3$ for C5. It is worth pointing out that the quantity of iron(III) chloride utilized in this multicomponent procedure is the smallest of all the ones from the literature protocols referenced herein. Nevertheless, the method afforded good yields for all the syntheses and proved to be successful either for the heteroaromatic aldehydes derivatives or for the benzaldehyde ones.

\section{CONCLUSION}

The development of this multicomponent procedure proved to be an efficient strategy for the synthesis of $R$-(+)-limonene-based 1,3,4-thiadiazoles. The low quantity of the oxidizing agent, different types of aldehydes employed and the good yields achieved when compared with other literature reports corroborate it.

\section{ACKNOWLEDGEMENTS}

CNPq and Fundação Araucária for financial support, CAPES and UEM-DQI.

\section{REFERENCES}

Kilburn, J. P.; Lau, J. and Jones, R. C. F. Tetrahedron Lett. 2003, 44, 7825 .

${ }^{2}$ Shih, M.-H. and Wu, C.-L. Tetrahedron. 2005, 61, 10917

${ }^{3}$ Kumar, D.; Vaddula, B. R.; Chang, K.-H. and Shah, K. Bioorg. Med. Chem. Lett. 2011, 21, 2320.

${ }^{4}$ Silva, C. C. da; Almagro, V. and Marsaioli, A. J. Tetrahedron Lett. 1993, $34,6717$.

${ }^{5}$ Yamaguchi, M. U.; da Silva, A. P. B.; Ueda-Nakamura, T.; Filho, B. P. D.; da Silva, C. C. and Nakamura, C. V. Molecules. 2009, 14, 1796. 